\title{
Antiplatelet Prescription in Atrial Fibrillation: Association with a Low Rate of Anticoagulation
}

\author{
Romain Chopard ${ }^{1}$ Samuel Z. Goldhaber ${ }^{1} \quad$ Neelima Karipineni $^{2} \quad$ Howard S. Goldberg $^{2} \quad$ Gregory Piazza $^{1}$ \\ ${ }^{1}$ Cardiovascular Division, Department of Medicine, Brigham and \\ Women's Hospital, Harvard Medical School, Boston, Massachusetts, \\ United States \\ 2 Division of General Internal Medicine, Brigham and Women's \\ Address for correspondence Romain Chopard, MD, PhD, \\ Cardiovascular Division, Department of Medicine, Brigham and \\ Women's Hospital, 75 Francis Street, Boston, MA 02115, \\ United States (e-mail: chopardromain@yahoo.fr).
} Hospital, Harvard Medical School, Boston, Massachusetts, United States

TH Open 2018;2:e229-e232.

Anticoagulants reduce the risk of thromboembolism and death in patients with atrial fibrillation (AF). ${ }^{1,2}$ Evidencebased clinical practice guidelines recommend anticoagulation based on the $\mathrm{CHA}_{2} \mathrm{DS}_{2}$-VASc score to decrease the risk of stroke in patients with $\mathrm{AF}^{3}$ Conversely, randomized trials demonstrate the inadequacy of antiplatelet agents compared with anticoagulants for stroke prevention in at-risk AF patients. ${ }^{4,5}$ We have reported in our AF outpatient cohort study that anticoagulants were prescribed in half of the patients with an indication for anticoagulation. ${ }^{6}$ We now analyze this database to determine clinical factors associated with non-prescription of anticoagulation in AF.

We reviewed 5,062 consecutive records of patients who had the diagnosis of AF entered into the electronic health record within our outpatient clinic network between March 2013 and March 2014. We utilized the 2011 American College of Cardiology/American Heart Association/ Heart Rhythm Society guidelines, which recommended anticoagulation in AF patients with a $\mathrm{CHA}_{2} \mathrm{DS}_{2}$-VASc score $\geq 2,{ }^{3}$ to narrow our final cohort to 3,677 patients. The aim of the study was to identify factors independently associated with nonprescription of anticoagulation for stroke prevention in AF patients with $\mathrm{CHA}_{2} \mathrm{DS}_{2}$-VASc score $\geq 2$. Anticoagulation was defined as the prescription of any United States Food and Drug Administration-approved anticoagulant therapy for stroke prevention in patients with AF. Vascular disease included coronary artery disease (CAD) and peripheral arterial disease (PAD). Bleeding risk was estimated with the modified HAS-BLED score, excluding fluctuation of the International Normalized Ratio (INR) because the computer program could not search for labile INR. ${ }^{7}$ To investigate associations with the nonprescription of anticoagulation, we undertook a multivariate analysis by constructing hierarchical modified Poisson's regression

received

February 27, 2018 accepted after revision

May 3, 2018 models with robust error variance, adjusted for patientand practice-level characteristics with a $p$-value of $<0.10$ by univariate analysis. ${ }^{8}$ Covariates entered into the model were age, sex, body mass index (BMI), race, ethnicity, hypertension, diabetes mellitus, heart failure (HF), CAD, PAD, chronic kidney disease, prior stroke, liver disease, prior major bleeding, alcoholism, and antiplatelet therapy. A relative risk greater than 1 corresponds to an increased probability of anticoagulation nonprescription. We identified factors related to prescription of antiplatelet therapy by using the same method. These models included site as a random effect to account for patient clustering within sites. Statistical tests were two sided and considered significant if they yielded a $p$-value of $<0.05$.

In total, 1,945 (52.9\%) patients were prescribed anticoagulation and 1,732 (47.1\%) were not. - Table 1 summarizes the baseline characteristics and antiplatelet regimen of the study population. Patients who were prescribed anticoagulation were older, had higher BMI, and presented with higher rates of hypertension, $\mathrm{HF}$, and prior stroke compared with those who did not receive anticoagulation by univariate analysis. These differences were reflected by higher $\mathrm{CHA}_{2} \mathrm{DS}_{2}$-VASc scores in the anticoagulant patient group (median [IQR]: 3 [3-5] vs. 3 [2-4]; $p<0.001$ ). Antiplatelet therapy was prescribed for $40.7 \%$ of patients not receiving anticoagulation and for $25.9 \%$ of those receiving anticoagulation $(p<0.001)$. Concomitant antiplatelet and anticoagulant therapies were more frequently prescribed in patients with vascular disease ( 48.5 vs. $20.9 \% ; p<0.001$ ). The proportion of patients receiving anticoagulation (with and without an antiplatelet agent) increased with $\mathrm{CHA}_{2} \mathrm{DS}_{2}$-VASc score $(p<0.001)$ and with HAS-BLED score $(p<0.001)$.

The rate of prescription of antiplatelet therapy alone did not vary significantly according to the $\mathrm{CHA}_{2} \mathrm{DS}_{2}$-VASc score,
License terms

Stuttgart · New York
DOI https://doi.org/

10.1055/s-0038-1660506. ISSN 2512-9465. 
Table 1 Baseline characteristics and antiplatelet regimen of atrial fibrillation patients at risk of stroke as categorized by the 2011 American College of Cardiology/American Heart Association/Heart Rhythm Society $\left(\mathrm{CHA}_{2} \mathrm{DS}_{2}\right.$-VASc score $\left.\geq 2\right)$ guidelines, stratified by prescription and nonprescription of anticoagulants

\begin{tabular}{|c|c|c|c|}
\hline \multirow[t]{3}{*}{ Characteristics } & \multicolumn{2}{|c|}{$\begin{array}{l}\mathrm{CHA}_{2} \mathrm{DS}_{2} \text {-VASc score } \geq 2 \\
(N=3,677)\end{array}$} & \multirow[t]{3}{*}{$p$-Value } \\
\hline & \multicolumn{2}{|l|}{ Anticoagulation } & \\
\hline & Yes $(N=1,945)$ & No $(N=1,732)$ & \\
\hline Mean age \pm SD, $y$ & $75.5 \pm 10.0$ & $74.0 \pm 10.7$ & 0.11 \\
\hline Male (\%) & $1,039(53.4)$ & $885(51.1)$ & 0.16 \\
\hline Mean BMI \pm SD, kg/m² & $29.3 \pm 6.5$ & $28.2 \pm 6.1$ & $<0.001$ \\
\hline \multicolumn{4}{|l|}{ Race (\%) } \\
\hline White & $1,586(81.5)$ & $1,442(83.3)$ & 0.17 \\
\hline Black & $125(6.4)$ & $81(4.7)$ & 0.02 \\
\hline Other & $117(6.0)$ & $91(5.2)$ & 0.35 \\
\hline \multicolumn{4}{|l|}{ Clinical history (\%) } \\
\hline Hypertension & $1,459(75.0)$ & 1,205 (69.6) & $<0.001$ \\
\hline Diabetes mellitus & $459(23.6)$ & $367(21.2)$ & 0.08 \\
\hline Heart failure & $463(23.8)$ & 309 (17.8) & $<0.001$ \\
\hline CAD & $574(29.5)$ & $514(29.7)$ & 0.91 \\
\hline Valvular heart disease & $361(18.6)$ & $293(16.9)$ & 0.19 \\
\hline PAD & $127(6.5)$ & $98(5.7)$ & 0.30 \\
\hline CKD & $189(9.7)$ & $194(11.2)$ & 0.14 \\
\hline Prior stroke & $293(15.1)$ & $149(8.6)$ & $<0.001$ \\
\hline Liver disease & $30(1.5)$ & $31(1.8)$ & 0.60 \\
\hline Prior major bleeding & $104(5.3)$ & $91(5.2)$ & 0.94 \\
\hline Alcoholism & $31(1.6)$ & $37(2.1)$ & 0.26 \\
\hline $\begin{array}{l}\text { Median } \mathrm{CHA}_{2} \mathrm{DS}_{2} \text {-VASc score } \\
\text { (Q1-Q3), points }\end{array}$ & $3(3-5)$ & $3(2-4)$ & $<0.001$ \\
\hline Median HAS-BLED score (Q1-Q3), points & $2(2-3)$ & $2(2-3)$ & 0.21 \\
\hline Any antiplatelet (\%) & $503(25.9)$ & $705(40.7)$ & $<0.001$ \\
\hline Dual-antiplatelet therapy (\%) & $40(2.3)$ & $<0.001$ & $<0.001$ \\
\hline
\end{tabular}

Abbreviations: BMI, body mass index; CAD, coronary artery disease; CKD, chronic kidney disease; PAD, peripheral artery disease; SD, standard deviation.

between $17.2 \%$ for the $\mathrm{CHA}_{2} \mathrm{DS}_{2}$-VASc score of 2 and $22.1 \%$ for the $\mathrm{CHA}_{2} \mathrm{DS}_{2}$-VASc score of $5(p=0.72)$. In contrast, the rate of antiplatelet prescription increased with the HAS-BLED score from $13.9 \%$ for HAS-BLED score of 1 to $54.1 \%$ for HASBLED score of 5 to 7 ( $p<0.001)$.

After multivariate adjustment, the only factor independently associated with non-prescription of anticoagulation was antiplatelet therapy (relative risk $[R R]=1.42$; $95 \%$ confidence interval $[\mathrm{CI}]=1.32-1.53)$. Increased age $(\mathrm{RR}=0.95$; 95\% CI $=0.92-0.98)$, increased BMI $(\mathrm{RR}=0.94 ; 95 \% \mathrm{CI}$ $=0.92-0.98)$, hypertension $(\mathrm{RR}=0.92 ; 95 \% \mathrm{CI}=0.85$ 0.99 ), $\mathrm{HF}(\mathrm{RR}=0.87 ; 95 \% \mathrm{CI}=0.81-0.93$ ), and previous stroke ( $\mathrm{RR}=0.77 ; 95 \% \mathrm{CI}=0.71-0.83$ ) were factors associated with increased frequency of anticoagulation prescription (-Fig. 1). Male sex $(\mathrm{RR}=1.05 ; 95 \% \mathrm{CI}=1.009-1.11)$, hypertension $(\mathrm{RR}=1.08 ; 95 \% \mathrm{CI}=1.03-1.14)$, and $\mathrm{CAD}$
$(\mathrm{RR}=1.52 ; 95 \% \mathrm{CI}=1.42-1.64)$ were associated with prescription of antiplatelet therapy.

Overall, we observed an inverse relationship between antiplatelet prescription and anticoagulant nonprescription. Other investigators have reported alcohol abuse, cancer, and falls as factors related to nonprescription of anticoagulation in addition to antiplatelet prescription. ${ }^{9}$

In our analysis, the rate of antiplatelet prescription alone was constant, regardless of stroke risk as defined by the $\mathrm{CHA}_{2} \mathrm{DS}_{2}$-VASc score. This suggests that antiplatelet therapy might have been prescribed for an indication other than stroke prevention, such as prevention of cardiovascular events, especially in patients with known vascular disease. Indeed, we identified risk factors for atherosclerosis (i.e., male gender and hypertension), along with CAD itself, as factors associated with prescription of antiplatelet 


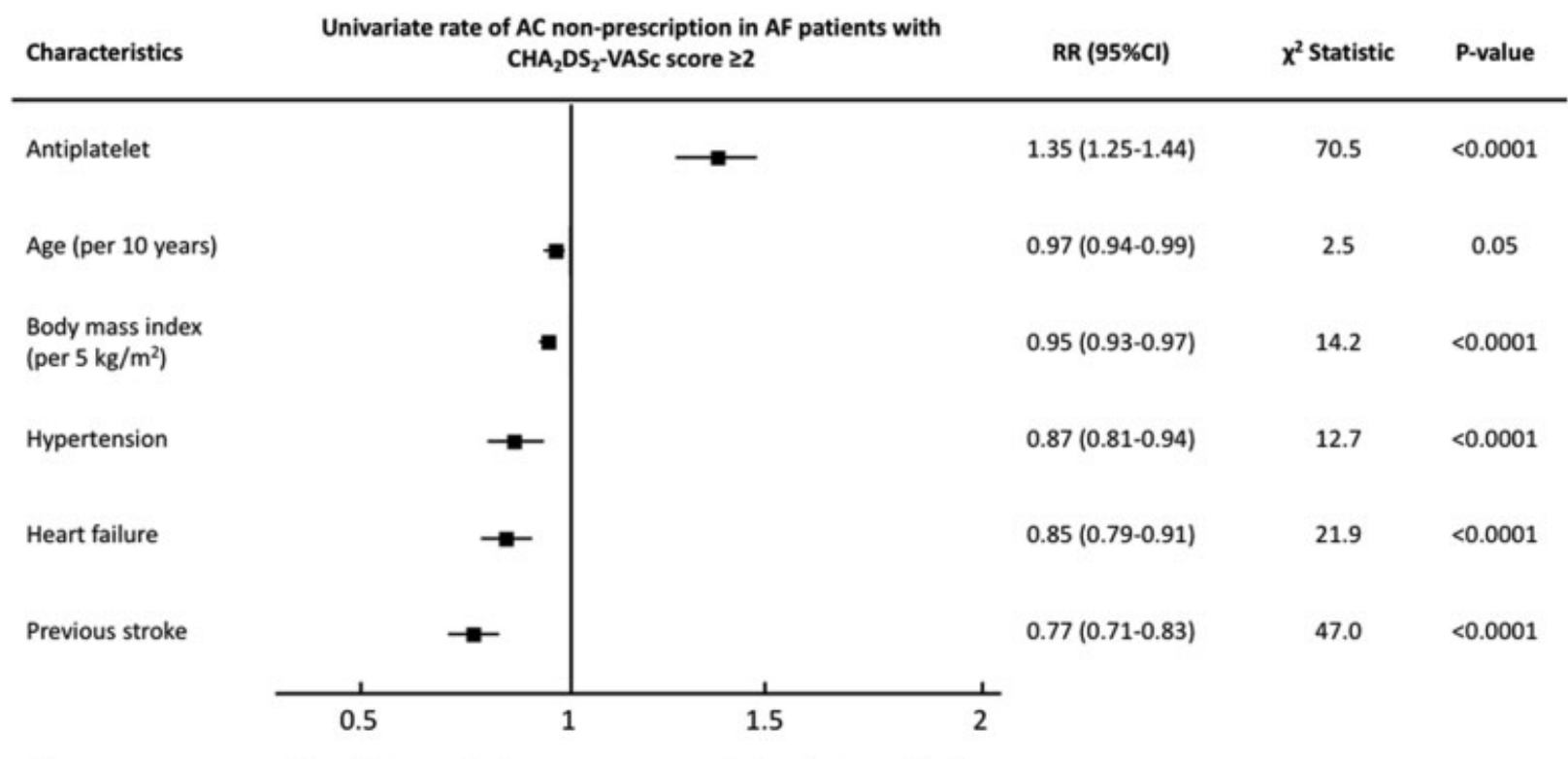

A «< Prescription of AC more likely Non-prescription of AC more likely »》

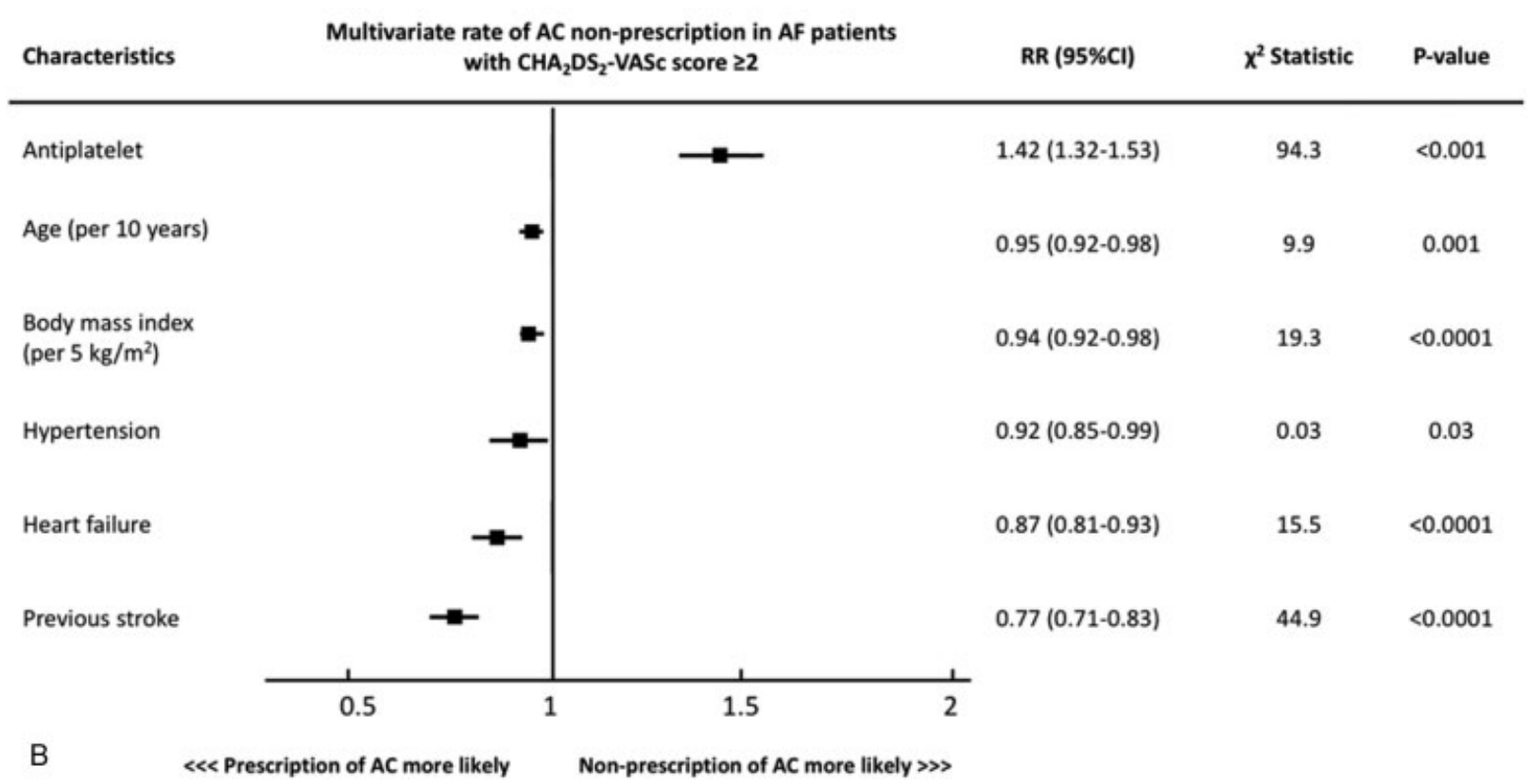

Fig. 1 Multivariate analysis of factors associated with anticoagulant nonprescription versus prescription in patients with atrial fibrillation at risk of stroke $\left(\mathrm{CHA}_{2} \mathrm{DS}_{2}\right.$-VASc score $\left.\geq 2\right)$. $A C$, anticoagulant; $\mathrm{AF}$, atrial fibrillation; $\mathrm{Cl}$, confidence interval; $\mathrm{RR}$, relative risk.

therapy. An analysis of the PINNACLE registry found, besides hypertension and CAD, that dyslipidemia and PAD were factors associated with prescription of aspirin rather than anticoagulation. ${ }^{10}$ Furthermore, the high rate of concomitant prescription of anticoagulant and antiplatelet agents in patients with vascular disease may reflect providers' concerns regarding the high risk of future vascular complications. We observed an increase in antiplatelet prescription alone in patients with a high HAS-BLED score, potentially because of concerns about causing bleeding with anticoagulant therapy. Other possible reasons for antiplatelet therapy prescription may include primary pre- vention in patients at high risk of cardiovascular disease, prevention of colon cancer, ${ }^{11}$ or patient's refusal of anticoagulation.

Our analysis has limitations. The precise reason that prompted the providers to prescribe antiplatelet therapy instead of guidelines-recommended anticoagulation was not recorded. The frailty status and life expectancy of the patients were not recorded. We do not have data regarding potential difficulties with warfarin management, which may have led to its discontinuation. Finally, we were unable to determine whether antiplatelet therapy was prescribed specifically for stroke prevention in AF or for some other reason. 
In conclusion, prescription of antiplatelet therapy was the only factor we identified that was associated with omission of anticoagulants in this study of AF outpatients at risk of stroke. Prevention of vascular events or concern for bleeding complications could be motivating factors for antiplatelet prescription rather than anticoagulation prescription. Factors compelling clinicians to prescribe antiplatelet therapy warrant consideration when assessing rates of anticoagulation in patients with AF.

\section{Conflicts of Interest}

Dr. Chopard has received research grant support from the French Federation of Cardiology, the Burgundy FrancheComte region, and Edwards Lifesciences.

Dr. Goldhaber has received research grant support from Boehringer Ingelheim, Bristol-Myers Squibb, Daiichi Sankyo, the Thrombosis Research Institute, and Janssen and consulting fees from Boehringer Ingelheim, Bristol-Myers Squibb, Daiichi Sankyo, Eisai, and Portola.

Dr. Piazza has received research grant support from Bristol Myers Squibb, Daiichi Sankyo, the Thrombosis Research Institute, and Janssen.

Drs. Karipineni and Goldberg have no relevant financial disclosures.

\section{References}

1 Hart RG, Pearce LA, Aguilar MI. Meta-analysis: antithrombotic therapy to prevent stroke in patients who have nonvalvular atrial fibrillation. Ann Intern Med 2007;146(12):857-867

2 Ruff CT, Giugliano RP, Braunwald E, et al. Comparison of the efficacy and safety of new oral anticoagulants with warfarin in patients with atrial fibrillation: a meta-analysis of randomised trials. Lancet 2014;383(9921):955-962
3 Wann LS, Curtis AB, Ellenbogen KA, et al. 2011 ACCF/AHA/HRS focused update on the management of patients with atrial fibrillation (update on dabigatran): a report of the American College of Cardiology Foundation/American Heart Association Task Force on practice guidelines. J Am Coll Cardiol 2011;57 (11):1330-1337

4 Connolly SJ, Eikelboom J, Joyner C, et al; AVERROES Steering Committee and Investigators. Apixaban in patients with atrial fibrillation. N Engl J Med 2011;364(09):806-817

5 Mant J, Hobbs FD, Fletcher K, et al; BAFTA investigators; Midland Research Practices Network (MidReC). Warfarin versus aspirin for stroke prevention in an elderly community population with atrial fibrillation (the Birmingham Atrial Fibrillation Treatment of the Aged Study, BAFTA): a randomised controlled trial. Lancet 2007; 370(9586):493-503

6 Piazza G, Karipineni N, Goldberg HS, Jenkins KL, Goldhaber SZ. Underutilization of anticoagulation for stroke prevention in atrial fibrillation. J Am Coll Cardiol 2016;67(20):2444-2446

7 Pisters R, Lane DA, Nieuwlaat R, de Vos CB, Crijns HJ, Lip GY. A novel user-friendly score (HAS-BLED) to assess 1-year risk of major bleeding in patients with atrial fibrillation: the Euro Heart Survey. Chest 2010;138(05):1093-1100

8 Zou G. A modified Poisson regression approach to prospective studies with binary data. Am J Epidemiol 2004;159(07): 702-706

9 Wilke T, Groth A, Pfannkuche M, et al. Real life anticoagulation treatment of patients with atrial fibrillation in Germany: extent and causes of anticoagulant under-use. J Thromb Thrombolysis 2015;40(01):97-107

10 Hsu JC, Maddox TM, Kennedy K, et al. Aspirin instead of oral anticoagulant prescription in atrial fibrillation patients at risk for stroke. J Am Coll Cardiol 2016;67(25):2913-2923

11 Bibbins-Domingo K; U.S. Preventive Services Task Force. Aspirin use for the primary prevention of cardiovascular disease and colorectal cancer: U.S. Preventive Services Task Force Recommendation Statement. Ann Intern Med 2016;164 (12):836-845 